\title{
One New Monoterpenoid from the Fruit of Gardenia Jasminoides
}

\author{
Yueming ZUO \\ College of Pharmacy \\ Jiangxi University of Traditional Chinese Medicines \\ Nanchang City, Jiangxi Province. China. 330004. \\ e-mail: zuo_yueming@163.com
}

\author{
Zhongli ZHANG* \\ College of Pharmacy \\ Jiangxi University of Traditional Chinese Medicines \\ Nanchang City, Jiangxi Province. China. 330004. \\ e-mail: zzl51518@163.com
}

\begin{abstract}
One new monoterpenoid, 5-aldehyde-6'-Osinapoyljasminoside A(1), together with two known compounds 6'O-sinapoyljasminoside $B(2)$ and 6'-O-trans-sinapoyljasminoside L(3), were isolated from the fruits of Gardenia jasminoides Ellis. The structures of the new monoterpenoid compound were elucidated by means of chemical evidence and 1D-and 2D-NMR $\left({ }^{1} \mathrm{H},{ }^{13} \mathrm{C}\right.$, HSQC, HMBC, ${ }^{1} \mathrm{H}^{1}{ }^{1} \mathrm{H}$ COSY and NOESY) spectroscopic analysis and HRESI-MS.
\end{abstract}

\section{Keywords-Gardenia jasminoides Ellis; Monoterpenoids}

\section{INTRODUCTION}

The fruit of Gardenia jasminoides Ellis (Rubiaceae) is widely used as a traditional Chinese medicine in China for its cholagogue, antiphlogistic, anxiolytic, diuretic, hemostatic, and against Alzheimer's disease[1,2,3]. In the previous papers, the chemical constituents from the fruits of $G$. jasminoides are reported to be triterpenoids[4], flavonoids[5], iridoids[6], and monoterpenoids[7],et al. This paper deals with the isolation and structural elucidation of one new monoterpenoid, 5aldehyde-6'- $O$-sinapoyljasmino-side $\mathrm{A}(1)$, along two known compounds 6'- $O$-sinapoyljasmi-noside B (2) and 6'- $O$-transsinapoyljasminoside L (3)[8-10], from the chloroform-soluble fractions of the $70 \%$ ethanol extract of the fruit of $G$. jasminoides.

\section{RESULTS AND DISCUSSION}

Compound $1, \mathrm{C}_{27} \mathrm{H}_{34} \mathrm{O}_{12}\left(\mathrm{M}^{+}\right.$at $m / z[\mathrm{M}+\mathrm{Na}]^{+}$573.1790), an amorphous powder. The ${ }^{1} \mathrm{H}-$ and ${ }^{13} \mathrm{C}-\mathrm{NMR}$ spectra of compound 1 revealed the presence of of an $\alpha, \beta$-unsaturated ketone $\left[\delta_{\mathrm{H}}: 6.16(1 \mathrm{H}, \mathrm{s}, \mathrm{H}-4) ; \delta_{\mathrm{C}}: 198.62(\mathrm{~s}, \mathrm{C}-3), 123.09(\mathrm{~s}\right.$, $\mathrm{C}-4)$ and $166.96(\mathrm{~s}, \mathrm{C}-5)]$, a methylene group adjacent to the $\alpha, \beta$-unsaturated ketone $\left[\delta_{\mathrm{H}}: 2.60(1 \mathrm{H}, \mathrm{d}, J=16.0 \mathrm{~Hz}, \mathrm{H}-\right.$ 2a)/1.87(1H, d, $\left.J=16.0 \mathrm{~Hz}, \mathrm{H}-2 \mathrm{~b}) ; \delta_{\mathrm{C}}: 48.54(\mathrm{~s}, \mathrm{C}-2)\right]$, an oxygenated methylene $\left[\delta_{\mathrm{H}}: 4.51(1 \mathrm{H}, \mathrm{dd}, J=1.2,16.8 \mathrm{~Hz}, \mathrm{H}-\right.$ $\left.7 \mathrm{a}) / 4.18(1 \mathrm{H}, \mathrm{d}, J=16.8 \mathrm{~Hz}, \mathrm{H}-7 \mathrm{~b}) ; \delta_{\mathrm{C}}: 69.56(\mathrm{~s}, \mathrm{C}-7)\right]$, a methylene $\left[\delta_{\mathrm{H}}: 1.93(1 \mathrm{H}, \mathrm{t}, J=4.0 \mathrm{~Hz}, \mathrm{H}-6) ; \delta_{\mathrm{C}}: 48.75(\mathrm{~s}, \mathrm{C}-\right.$ 6)], a vinyl aldehyde $\left[\delta_{\mathrm{H}}: 8.99(1 \mathrm{H}, \mathrm{s}, \mathrm{H}-8) ; \delta_{\mathrm{C}}: 161.57(\mathrm{~s}, \mathrm{C}-\right.$ 8)]. Further, NMR analysis showed the presence of two methyl groups attached to a quaternary carbon $\left[\delta_{\mathrm{H}}: 0.92(3 \mathrm{H}\right.$, $\left.\mathrm{s}, \mathrm{CH}_{3}-9\right), 1.07\left(3 \mathrm{H}, \mathrm{s}, \mathrm{CH}_{3}-10\right) ; \delta_{\mathrm{C}}: 28.32\left(\mathrm{~s}, \mathrm{CH}_{3}-9\right)$, 26.62(s, $\left.\left.\mathrm{CH}_{3}-10\right), 34.91(\mathrm{~s}, \mathrm{C}-1)\right]$. These data suggested that 1 was a basic parent nucleus of 5-aldehyde-jasminoside A $[8,9,10]$. The $\beta$-linkage of the glucosidic unit was consistent with the coupling constant of the anomeric proton at $\delta_{\mathrm{H}}: 4.27\left(1 \mathrm{H}, \mathrm{d}, J=7.6 \mathrm{~Hz}, \mathrm{H}-1^{\prime}\right)$. The chemical shifts of the six carbons at $\delta_{\mathrm{C}}$ : $102.80\left(\mathrm{~s}, \mathrm{C}-1^{\prime}\right), 73.45\left(\mathrm{~s}, \mathrm{C}-2^{\prime}\right), 76.35$ (s, C-3'), 69.92 (s, C-4'), 73.79 (s, C-5'), 63.41 (s, C-6') in the ${ }^{13} \mathrm{C}-\mathrm{NMR}$ indicated that the suger was a $1^{\prime}, 6^{\prime}-$ disubstituted glucose[8,9,10].The above date suggested that the structure of 1 was jasminoside A with a sinapoyl moiety connected to 6 '-OH of the glucosyl moiety[8, 9, 10]. On the basis of the above data, the structure of 1 was determined to be as 5-aldehyde-6'- $O$-sinapoyljasminoside $\mathrm{A}$ and be as depicted in Table I.

\section{EXPERIMENTAL}

\section{A. General}

HR-ESI-MS were recorded in a Finnigan-LC-QDECA. NMR spectra were recorded on Bruker AM-400. TLC employed precoated silica gel plates $(5-7 \mu \mathrm{m}$, Qingdao Haiyang). For column chromatography, silica gel (H, 100200 and 200-300 mesh, Qingdao Haiyang). HPLC was performed on a waters 515 instrument equipped with a water-UV-2489 detector. A YMC-pack ODS-A $(10 \times 250$ $\mathrm{mm}$, i.d.) column was used for preparative purpose. Compounds were visualized either under UV light or by spraying with $10 \% \mathrm{H}_{2} \mathrm{SO}_{4}$ followed by heating at $90^{\circ} \mathrm{C}$ for 5-10 min.

\section{B. Plant Material}

The fruits of Gardenia jasminoides were collected from Zhangshu City of Jiangxi province, People's Republic of China in October 2010 and identified by prof. Yueming Zuo of Jiangxi University of Traditional Chinese Medicines. The voucher specimen (JZ20101021) was deposited at College of Pharmacy, Jiangxi University of Traditional Chinese Medicines, China.

\section{Extraction and Isolation}

The dried fruits $(50 \mathrm{Kg})$ of Gardenia jasminoides were successively extracted 6 times with $80 \%$ ethanol (each $300 \mathrm{~L} \times 3$ ) under reflux for $2 \mathrm{~h}$. The ethanol extracts was combined and evaporated under reduced pressure to afford crude extracts $(10 \mathrm{~kg})$ and the residue $(6 \mathrm{~kg})$ was suspended in water(12L). This suspension was successively extracted with Petroleum ether, $\mathrm{CHCl}_{3}$, EtOAc and $\mathrm{n}-\mathrm{BuOH}$ to give the corresponding Petroleum ether(125g), $\quad \mathrm{CHCl}_{3}(314 \mathrm{~g})$, EtOAc(480g) and $\mathrm{n}-\mathrm{BuOH}(800 \mathrm{~g})$ extracts. The n-BuOHsoluble fraction (750g) was applied to a silica gel colum using a $\mathrm{CHCl}_{3}-\mathrm{MeOH}(100: 1$ to $0: 1)$ gradient solvent system to give 50 fractions (1-50).Fr.43 was separated by 
$\mathrm{CC}$ (silica gel; $\mathrm{CHCl}_{3} / \mathrm{MeOH}$ 5:1 to 0:1) and preparation of high performance liquid chromatography $\left(\mathrm{MeOH} / \mathrm{H}_{2} \mathrm{O} 1: 10\right)$ to afford compound $1(8 \mathrm{mg})$. Fr.42 was separated by $\mathrm{CC}$ (silica gel; $\mathrm{CHCl}_{3} / \mathrm{MeOH}$ 5:1 to 0:1) and preparation of high performance liquid chromatography $\left(\mathrm{MeOH} / \mathrm{H}_{2} \mathrm{O} 1: 10\right)$ to afford compound $2(10 \mathrm{mg})$. Fr.44 was separated by $\mathrm{CC}$ (silica gel; $\mathrm{CHCl}_{3} / \mathrm{MeOH} 5: 1$ to 0:1) and preparation of high performance liquid chromatography $\left(\mathrm{MeOH} / \mathrm{H}_{2} \mathrm{O}\right.$ 1:10) to afford compound $3(6 \mathrm{mg})$.

(1) 5-aldehyde-6'- $O$-sinapoyljasminoside A

An amorphous powder:

${ }^{1} \mathrm{H}$ and ${ }^{13} \mathrm{C}$-NMR (DMSO- $d_{6}$ ): Table I.

Positive EIS-MS: $\mathrm{m} / z$ $573[\mathrm{M}+\mathrm{Na}]^{+}$,HR-ESI-MS: $\mathrm{m} / z$

$[\mathrm{M}+\mathrm{Na}]^{+} 573.1790\left(\mathrm{C}_{27} \mathrm{H}_{34} \mathrm{O}_{12}\right)$.

(2) 6'-O-sinapoyljasminoside $\mathrm{B}$

An amorphous powder:

Positive EIS-MS: $m / z$ 553[M+H] ${ }^{+}$,HR-ESI-MS: $m / z$

$[\mathrm{M}+\mathrm{H}]^{+} 553.2284\left(\mathrm{C}_{27} \mathrm{H}_{36} \mathrm{O}_{12}\right)$.

(3) 6'-O-trans-sinapoyljasminoside $\mathrm{L}$

An amorphous powder:

Positive EIS-MS: $m / z 575[\mathrm{M}+\mathrm{Na}]^{+}$, HR-ESI-MS: $\mathrm{m} / \mathrm{z}$

$[\mathrm{M}+\mathrm{Na}]^{+} 575.2102\left(\mathrm{C}_{27} \mathrm{H}_{36} \mathrm{O}_{12}\right)$.

\section{CONCLUSIONS}

We investigated the chemical constituents of Gardenia jasminoides. and three Monoterpene glycosides were obtained. Their structures were identified as 5-aldehyde-6'$O$-sinapoyljasminoside A (1), 6'- $O$-sinapoyljasminoside $\mathrm{B}(2)$ and 6 '- $O$-trans-sinapoyljasminoside L(3), respectively. This study will contribute to revealing the chemical basis for the therapeutic effect of Gardenia jasminoides.

\section{ACKNOWLEDGMENT}

The authors acknowledge the financial support of the National Natural Science Foundation of China (NSFC), (No.81360632).

\section{REFERENCES}

[1] Tang, W.; Eisenbrand, G. Chinese Drugs of Plant Origin-Gardenia jasminoides Ellis; Springer-Verlag: Berlin, 1992:539-54.

[2] Yang Yu, Zuo-lei Xie, Hao Gao, Wei-wei Ma, Yi Dai, Ying Wang, Yi Zhong, and Xin-sheng Yao*. Bioactive Iridoid Glucosides from the fruit of Gardenia jasminoides [J].J.Nat.Prod, 2009, 72(8):14591464.

[3] ZUO Yue-ming, CAI Miao-ting, ZHANG Zhong-Li*, LUO Guangming. Effect of extracts from Gardenia jasminoides Ellis on spatial learning memory in rat model of Heterogeneity/Multi-factors Alzheimer's Disease [J]. LISHIZHEN MEDICINE AND MATERIA MEDICA RESEARCH, 2014, 25(9):2055-2057.

[4] ZHANG Zhong-Li, ZUO Yue-ming, LUO Guang-ming*, FU Xiaomei, CAI Cai-jun, WANG Yan-yan. Studies on the Chemical Components of Triterpenoids of Gardenia jasminoides Ellis [J] LISHIZHEN MEDICINE AND MATERIA MEDICA RESEARCH, 2013, 24(2):338-339.

[5] ZHANG Zhong-li, ZUO Yue-ming, YANG Ya-qin, LUO Guangming*, CAI Cai-jun, XIONG Shi-hua. Studies on Chemical Components of Flavonoids of Gardenia jasminoides Ellis [J]. Chinese Journal of Experimental Traditional Medical Formulae, 2013, 19(4):79-81.

[6] CAI Cai-jun, ZHANG Zhong-Li, ZUO Yue-ming, ZHU Yu-ye, LUO Guang-ming*, ZHANG Jian.Studies on the Chemical Components of Iridoids of Gardenia jasminoides Ellis [J]. LISHIZHEN MEDICINE AND MATERIA MEDICA RESEARCH, 2013, 24(2):342-343.

[7] ZUO Yue-ming, ZHANG Zhong-Li, YANG Ya-qin, LUO Guangming*, WANG Yan-yan. Chemical constituents of monoterpenes in fruits of Gardenia jasminoides [J]. Chinese Traditional and Herbal Drugs, 2013, 44(13):1730-1733.

[8] YU Yang. Studies on Chemical Constituents of Gardenia jasminoides for the Treatment of Alzheimer's Diseases [D]. Shenyang: Doctorate Dissertation of Shenyang Pharmaceutical University, 2010:65-72.

[9] Quan Cheng Chen, Ui Joung Youn, Byung-Sun Min, and KiHwan Bae. Pyronane Monoterpenoids from the Fruit of Gardenia jasminoides [J]. Journal of Natural Products, 2008, 71(6):995-999.

[10] Koichi MACHIDA, Rie ONODERA, Kyoko FURUTA, and Masao KIKUCHI. Studies of the constituents of Gardenia jasminoides I. Monoterpenoids from Gardeniae Fructus[J]. Chem.Pharm.Bull,1998, 46(8):1295-1300.
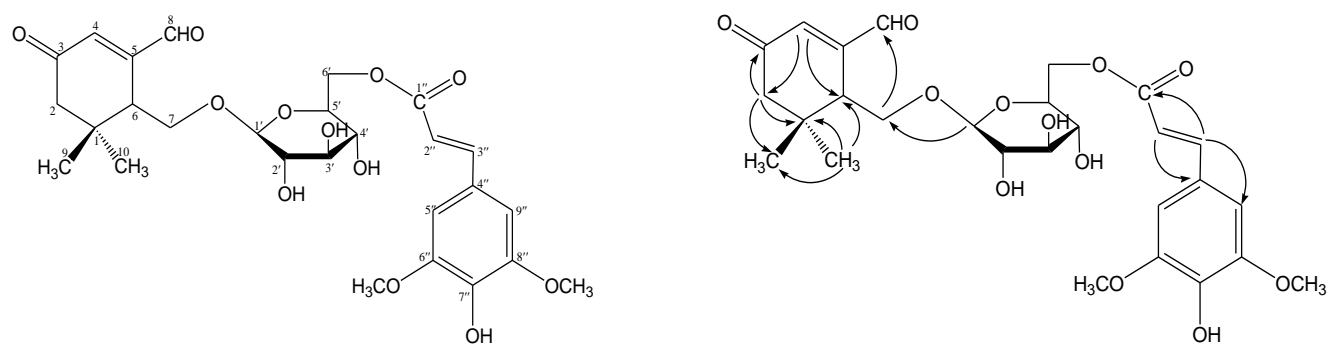

Figure.1.Structure and Key HMBC correlations of compound $1(\mathrm{H} \rightarrow \mathrm{C})$ 
TABLE I. ${ }^{1} \mathrm{H}-\mathrm{NMR}(400 \mathrm{MHZ})$ AND ${ }^{13} \mathrm{C}-\mathrm{NMR}(100 \mathrm{MHZ})$ SPECTROSCOPIC DATA OF COMPOUNDS 1 (DMSO-D ${ }_{6}$ )

\begin{tabular}{|c|c|c|c|}
\hline \multirow[b]{2}{*}{ position. } & \multicolumn{3}{|c|}{1} \\
\hline & $\delta \mathrm{C} / \mathrm{pmm}$ & $\delta \mathrm{H}(\mathrm{J}) / \mathrm{pmm}$ & HMBC \\
\hline 1 & 34.91 & & \\
\hline \multirow[t]{2}{*}{2} & 48.75 & $2.60, d(16.0)$ & $\mathrm{C}-3$ \\
\hline & & $1.87, \mathrm{~d}(16.0)$ & $\mathrm{C}-3$ \\
\hline 3 & 198.62 & & \\
\hline 4 & 123.09 & $6.16, \mathrm{~s}$ & \\
\hline 5 & 166.96 & & \\
\hline 6 & 48.54 & $1.93, \mathrm{t}(4.0)$ & \\
\hline \multirow[t]{2}{*}{7} & 69.56 & $4.51, \mathrm{dd}(1.2,16.8)$ & C- 8 \\
\hline & & $4.18, \mathrm{~d}(16.8)$ & C- 8 \\
\hline 8 & 161.57 & $8.99, \mathrm{~s}$ & \\
\hline 9 & 28.32 & $0.92, \mathrm{~s}$ & $\mathrm{C}-1, \mathrm{C}-2, \mathrm{C}-10$ \\
\hline 10 & 26.62 & $1.00, \mathrm{~s}$ & C-1, C-6, C-9 \\
\hline $1^{\prime}$ & 102.80 & $4.27, \mathrm{~d}(7.6)$ & C-7 \\
\hline $2^{\prime}$ & 73.45 & $3.07, \mathrm{~m}$ & \\
\hline $3^{\prime}$ & 76.33 & $3.19, \mathrm{~m}$ & \\
\hline $4^{\prime}$ & 69.92 & $3.17, \mathrm{~m}$ & \\
\hline $5^{\prime}$ & 73.79 & $3.41, \mathrm{~m}$ & \\
\hline \multirow[t]{2}{*}{$6^{\prime}$} & 63.41 & $4.37, \mathrm{dd}(2.8,12.0)$ & \\
\hline & & $4.17, \mathrm{~m}$ & \\
\hline $1 "$ & 166.63 & & \\
\hline $2 "$ & 114.70 & $6.56, \mathrm{~d}(16.0)$ & C-5" \\
\hline $3 "$ & 145.54 & $7.56, \mathrm{~d}(16.0)$ & C-4",C-9" \\
\hline $4 "$ & 124.33 & & \\
\hline $5 "$ & 106.22 & $7.05, \mathrm{~s}$ & C-7",C-8", C-9" \\
\hline $6 "$ & 147.97 & & \\
\hline 7" & 138.28 & & \\
\hline $8 "$ & 147.97 & & \\
\hline 9" & 106.22 & $7.05, \mathrm{~s}$ & C-5",C-6", C-7" \\
\hline 6"--OCH & 56.04 & $3.81, \mathrm{~s}$ & C-6" \\
\hline 8"--OCH & 56.04 & $3.81, \mathrm{~s}$ & C-8" \\
\hline
\end{tabular}

